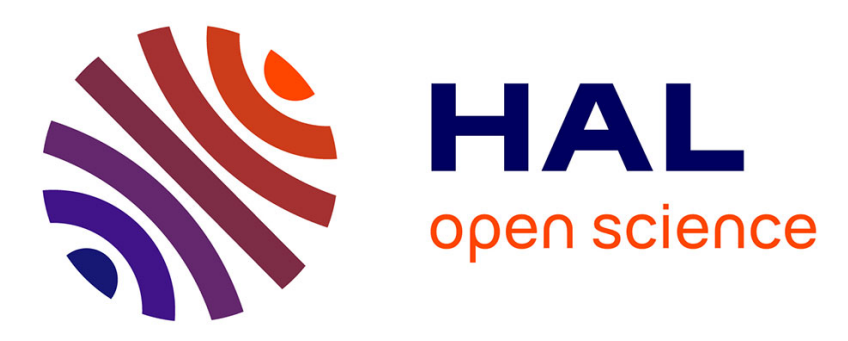

\title{
Protein-induced satiety is abolished in the absence of intestinal gluconeogenesis.
}

Armelle Penhoat, Elodie Mutel, Marta Amigo-Correig, Bruno Pillot, Anne Stefanutti, Fabienne Rajas, Gilles Mithieux

\section{To cite this version:}

Armelle Penhoat, Elodie Mutel, Marta Amigo-Correig, Bruno Pillot, Anne Stefanutti, et al.. Proteininduced satiety is abolished in the absence of intestinal gluconeogenesis.. Physiology \& behavior, 2011, 105 (1), pp.89-93. 10.1016/j.physbeh.2011.03.012 . inserm-00737429

HAL Id: inserm-00737429 https://www.hal.inserm.fr/inserm-00737429

Submitted on 1 Oct 2012

HAL is a multi-disciplinary open access archive for the deposit and dissemination of scientific research documents, whether they are published or not. The documents may come from teaching and research institutions in France or abroad, or from public or private research centers.
L'archive ouverte pluridisciplinaire HAL, est destinée au dépôt et à la diffusion de documents scientifiques de niveau recherche, publiés ou non, émanant des établissements d'enseignement et de recherche français ou étrangers, des laboratoires publics ou privés. 
Armelle Penhoat ${ }^{1-3}$, Elodie Mutel $^{1-3}$, Marta Amigo-Correig ${ }^{1-3}$, Bruno Pillot ${ }^{1-3}$, Anne Stefanutti $^{1-3}$, Fabienne Rajas $^{1-3}$, Gilles Mithieux ${ }^{1-3}$

${ }^{1}$ Institut National de la Santé et de la Recherche Médicale, U855, Lyon, F-69008, France

${ }^{2}$ Université de Lyon, Lyon, F-69008 France

${ }^{3}$ Université Lyon 1, Villeurbanne, F-69622 France

Address for correspondence: $\quad$ Dr. Gilles Mithieux Inserm U855/Université Lyon 1 Faculté de Médecine Laennec 7 rue Guillaume Paradin 69372 Lyon cedex 08 France Tel: 334787787 88/Fax: 33478778762 E-mail: gilles.mithieux@univ-lyon1.fr

Abbreviations used: Glucose-6 phosphatase (G6Pase), Catalytic subunit of G6Pase (G6PC), starch-enriched diet (SED), protein-enriched diet (PED)

\section{Research highlights}

- New model of mice with specific G6Pase gene knockout in the intestine

- Molecular evidence of the regulatory role of intestinal gluconeogenesis in the control of food intake

- Intestinal gluconeogenesis is a causal link in protein-induced satiety 


\section{Keywords}

Glucose-6 phosphatase, gluconeogenesis, intestine, protein-enriched diet, food intake,

\section{Abstract}

Protein-enriched diets are well known to initiate satiety effects in animals and humans. It has been recently suggested that this might be dependent on the induction of gluconeogenesis in the intestine. The resulting intestinal glucose release, detected by a "so-called" glucose sensor located within the walls of the portal vein and connected to peripheral afferents, activates hypothalamic nuclei involved in the regulation of food intake, in turn initiating a decrease in hunger. To definitively demonstrate the role of intestinal gluconeogenesis in this mechanism, we tested the food intake response to a protein-enriched diet in mice with an intestine-specific deletion (using an inducible Cre/loxP strategy) of the glucose-6 phosphatase gene (I-G6pc-/mice) encoding the mandatory enzyme for glucose production. There was no effect on food intake in I-G6pc $c^{-/-}$mice fed on a standard rodent diet compared to their wild-type counterparts. After switching to a protein-enriched diet, the food intake of wild-type mice decreased significantly (by about $20 \%$ of daily calorie intake), subsequently leading to a decrease of 12 $\pm 2 \%$ of initial body weight after 8 days. On the contrary, I-G6pc $c^{-/-}$mice were insensitive to the satiety effect induced by a protein-enriched diet and preserved their body weight. These results provide molecular evidence of the causal role of intestinal gluconeogenesis in the satiety phenomenon initiated by protein-enriched diets. 


\section{1-Introduction}

The massive development of obesity in western countries makes it increasingly crucial to better understand its underlying mechanisms. These include food intake disorders which are assumed to play a major role. In this context, the well-known satiety effect induced by protein-enriched diets in animals and humans has long been used to help obese subjects to decrease their sensation of hunger and lose weight [1-3]. Despite the number of studies dealing with the decrease of hunger induced by food proteins, the mechanisms by which the latter produce their satiety effects remain poorly understood [4-6]. Recently, we strongly suggested from studies in rats that the induction of intestinal gluconeogenesis provides a physiological explanation for the satiety effects induced by protein-enriched diets [7]. The existence of intestinal gluconeogenesis was demonstrated 10 years ago [8-10] and has been confirmed in humans $[11,12]$ and other species [13]. The three key regulatory enzymes of gluconeogenesis, namely glucose-6-phosphatase (G6Pase), cytosolic phosphoenolpyruvate carboxykinase and glutaminase, appeared to be strongly induced in the small intestine of rats fed on a protein-enriched diet (PED) [7]. This induction of gluconeogenic genes in the small intestine resulted in a portal release of glucose, lasting during the post-absorptive period in rats fed on the PED. The reduction of food intake consecutive to portal infusions of glucose has been reported in several previous studies on rats [14-16]. Moreover, portal infusions of glucose modify the electrical activity of portal afferents and neurons in the central area involved in the control of food intake [17-19]. In the particular case of PED in rats, the amount of glucose released by the gut accounted for no more than about $20 \%$ of total glucose occurrence in the whole body [7]. This portal glucose flux, however, was sufficient to be sensed by a "so-called" portal glucose sensor connected to afferents surrounding the portal vein and which activate the hypothalamic nuclei involved in the regulation of food intake, 
thereby causing a decrease in subsequent food consumption [7, see 20-21 for recent reviews]. Interestingly, intestinal gluconeogenesis has also provided a mechanistic explanation for the hunger-curbing effects known to take place in another particular nutritional situation. Hence morbidly obese patients having undergone gastric bypass surgical procedures, rapidly report a decrease of their hunger sensations [22]. The induction of intestinal gluconeogenesis has been strongly suggested to account for the satiety effects and decreased food intake in a gastric bypass model in mice [23, 24 for recent review].

To definitively demonstrate the role of intestinal gluconeogenesis in controlling food intake, we developed a transgenic mouse model with time-dependent inactivation of this function specifically in the small intestine, by using a Cre/loxP strategy. To this end, we targeted the gene encoding the glucose-6 phosphatase catalytic subunit (G6PC), the key enzyme of gluconeogenesis, which governs the last biochemical reaction preceding the release of glucose by the organ. In this work, we tested whether the potency of PED to decrease food intake might be blunted after suppression of the capacity of the intestine to perform gluconeogenesis.

\section{2-Material and methods}

\section{2-1 Generation of intestine-specific G6pc-null mice}

B6.g6pc ${ }^{\text {lox/w }}$ mice, in which exon 3 of G6pc gene was surrounded by two loxP sites (Figure 1A) [25], were crossed with transgenic B6.vill ${ }^{\text {creERT2/w }}$ mice, expressing inducible Cre ${ }^{\text {ERT2 }}$ recombinase under the control of the villin promoter [26]. The litters were genotyped at ten days old from tail genomic DNA analysis by PCR with specific primers as described previously [25]. Heterozygous $\mathrm{B} 6 . \mathrm{g} 6 \mathrm{pc}^{\text {lox/w }} \cdot$ vill $^{\text {creERT2/w }}$ mice were crossed to generate 
homozygous mice. To induce the excision of the G6pc exon 3, male adult (7-8 week-old) B6.g6pc ${ }^{\text {lox/lox }} \cdot$ vill $^{\text {creERT2/w }}$ mice were injected intraperitoneally once daily with $100 \mu 1$ tamoxifen (10mg/ml, Sigma-Aldrich) on five consecutive days to obtain I-G6pc ${ }^{-/-}$mice. Wildtype $\mathrm{C} 57 \mathrm{Bl} / 6 \mathrm{~J}$ (WT) mice were treated similarly to obtain control mice. All the mice were housed in the animal facility of Lyon 1 University (Animaleries Lyon Est Conventionnelle et SPF) under controlled temperature $\left(22^{\circ} \mathrm{C}\right)$ conditions with a 12-hour light-12-hour dark cycle. The mice had free access to water and to a standard rodent starch-enriched diet (SED, Harlan).

All the procedures were performed in accordance with the principles and guidelines established by the European Convention for the Protection of Laboratory Animals. The regional animal care committee (CREEA, CNRS, Rhône-Alpes Auvergne, France) approved all the experiments.

2-2 Food intake and body weight measurements

Mice were individually housed with food and water ad libitum. Food consumption and body weight were monitored every day for two weeks. The composition of the diets was essentially based on that of a standard rodent diet with modifications in the starch-glucose/protein ratio, which were $65 \% / 20 \%$ in SED and $20 \% / 65 \%$ in protein-enriched diet (PED, Safe) (energy basis). The PED was isocaloric for SED (3.3 kcal/g). Proteins were a mixture of soya protein and casein (50/50).

\section{2-3 Gene expression analyses}

Mice were killed by cervical dislocation in the post-absorptive state (6h after food removal). Tissues were rapidly removed and frozen using tongs previously chilled in liquid $\mathrm{N}_{2}$. The frozen tissues were kept at $-80^{\circ} \mathrm{C}$ until use. Total RNAs were isolated from tissues with 
TRIzol reagent (Invitrogen). Reverse transcription and real-time PCR were performed as described previously [27], by using sequence-specific primers (Table 1). The mouse ribosomal protein $\mathrm{mL} 19$ transcript (Rpl19) was used as a reference. G6Pase activity was assayed under conditions of maximal velocity, according to a procedure reported previously $[10]$.

\section{2-4 Statistical analyses}

Results are reported as means \pm SEM. The different groups were compared by Mann-Whitney tests.

\section{3-Results and discussion}

3-1 Initiation of intestine-specific deficiency of G6Pase in mice

We disrupted G6Pase specifically in the intestine, by a time-dependent and tissuespecific knockout of the G6pc gene, based on the same Cre/lox strategy as described previously by Mutel et al [25]. The transgenic B6.g6 $\mathrm{pc}^{\mathrm{lox} / \mathrm{w}}$ mice were crossed with transgenic B6.vill ${ }^{\text {creERT2/w}}$ mice to generate heterozygous B6.g6 $\mathrm{pc}^{\text {lox/w }} \cdot$ vill $^{\text {creERT2/w }}$ mice. These mice express the inducible $\mathrm{Cre}^{\mathrm{ERT} 2}$ recombinase under the control of the villin promoter, conferring them with intestine-specific expression of the recombinase [26]. The mice were genotyped by PCR analysis of tail genomic DNA (Figure 1B). Treatment of male homozygous B6.g6pc ${ }^{\text {lox/lox }}$. vill $^{\text {creERT2/w }}$ mice with tamoxifen at 7-8 weeks old resulted in the specific excision of exon 3 from G6pc alleles in the small intestine, generating a 595 bp PCR fragment from the I-G6pc-/- mice (Figure 1C). In the liver and kidney, the two other gluconeogenic tissues expressing G6pc, the same PCR amplification generated a 1189 bp fragment from the $\mathrm{I}-G 6 p c^{-/-}$mice, confirming the specific deletion in the small intestine (Figure 1C). Comparable 
data were obtained at one week and up to fourteen weeks after the tamoxifen injections, confirming the persistence of the specific G6pc gene knockout in the small intestine. The truncated G6pc mRNA appeared to be strongly up-regulated, with 2.5 times more G6pc mRNA in the small intestine of I-G6pc ${ }^{-/-}$mice than in controls (Figure 2A). This could be accounted for by a compensatory increase in gene expression in the absence of G6PC protein, as was also observed in the liver when the specific G6pc knockout was done in this organ [25]. To obviate the absence of G6PC protein, we assayed G6Pase activity in the proximal jejunum of WT and I-G6pc $c^{-/}$mice. In WT mice, the jejunum G6Pase activity was doubled after 3 days of feeding on PED (Figure 2B). This was comparable to what has been reported in the rat [7]. Residual non specific G6Pase activity was present in I-G6pc $c^{-/-}$mice, comparable to that which could be measured in non-gluconeogenic organs $[28,29]$. This might be accounted for by the presence of G6PC3 (Figure 2D), a ubiquitous glucose-6-phosphataserelated protein exhibiting weak G6Pase activity in vitro, but having no gluconeogenic role in vivo [30 for review]. This activity was not increased by PED feeding (Figure 2B) in agreement with the assumption that this low activity was not representative of "gluconeogenic" specific G6Pase activity. The expression of G6pt (Slc37a4) and G6pc3 genes, encoding the glucose-6 phosphate translocase and the G6PC3, respectively, was unaffected, as was observed in the liver-specific G6pc knockout mice (Figure 2C and D) [25].

\section{3-2 Absence of reduced food intake by protein-enriched diet in I-G6pc $c^{-/-}$mice}

Male I-G6pc ${ }^{-/-}$mice exhibited a growth rate similar to that of WT mice, when fed on a standard rodent starch-enriched diet (SED). One week after intestinal G6pc knockout, food intake and body weight were monitored over 13 successive days. The I-G6pc ${ }^{-/-}$and WT mice were matched for age at the beginning of the experiment. The body weight of I-G6pc $c^{-/-}$was similar to that of the control mice (Figure 3C). During the first five days, the I-G6pc ${ }^{-/-}$mice 
fed on SED ate like the WT mice $\left(12.4 \pm 0.5 \mathrm{kcal} / \mathrm{day} /\right.$ mouse in the I-G6pc ${ }^{-/-}$mice versus 11.6 $\pm 0.5 \mathrm{kcal} / \mathrm{day} / \mathrm{mouse}$ in the control mice) and their body weight was constant, as was that of WT mice (Figure 3A and C). Then, the SED (20\% energy intake from protein) was replaced by a PED (65\% energy intake from protein) and the mouse food intake was monitored for another week. As with the WT mice, the I-G6pc $c^{-/}$mice fed on PED ate slightly less the first day it was given to them (reduction of $22 \%$ and $15 \%$ of food intake, respectively). This lower food intake in PED-fed mice was comparable to that reported previously in rats [7]. As described previously in rats, the WT mice ate about $20 \%$ less with the PED than with the SED and this lower food intake was maintained throughout the experiment (Figure 3A). In contrast, after an initial decrease in food intake, consecutive to the change in diet, the food intake of I-G6pc ${ }^{-/-}$mice fed on PED rapidly increased to reach the same level as that previously observed when they were fed on SED (Figure 3A). Moreover, the accumulated food intake, which was exactly the same in both I-G6pc $c^{-/}$and WT animals fed on SED, became significantly different from the first day after switching to PED (Figure 3B). In parallel, the body weight of $\mathrm{I}-G 6 p c^{-/-}$mice was stable throughout the PED $(25.4 \pm 0.4$ $\mathrm{g} /$ mouse versus $25.8 \pm 0.3 \mathrm{~g} /$ mouse at day 6 and at day 13, respectively; Figure $3 \mathrm{C}$ ), whereas the body weight of WT mice decreased significantly after 5 days on PED (Figure 3C). After 8 days on PED, the WT mice lost around $3 \mathrm{~g}$ /mouse, i.e. a decrease of $12 \pm 2 \%$ of their initial body weight (Figure 3C). These results therefore demonstrate that mice with specific knockout of the G6pc gene in the intestine are no longer sensitive to the satiety effect induced by food proteins. The G6Pase catalytic subunit is the mandatory enzyme for endogenous glucose production from the three gluconeogenic organs of the body. In agreement with this assumption, mice with total G6pc knockout die shortly after weaning [31] and patients with inherited deficiency in G6PC (glycogen storage disease type 1a) suffer from severe hypoglycaemic episodes if not frequently fed with oral carbohydrates [30 for review]. 
Moreover, mice with liver-specific G6pc knockout rapidly develop the hepatic features of the GSD1a pathology [25]. It can therefore be inferred that mice with specific deletion of G6pc in the intestine are unable to release glucose from intestinal biochemical pathways. Therefore, this novel I-G6pc $c^{-/-}$mouse model allowed us to definitively strengthen the paradigm that the satiety signal induced by food proteins can be accounted for by a portal glucose release from intestinal gluconeogenesis. What is particularly noteworthy about this phenomenon is that there are long-term changes in body weight that occur if PED-feeding is continued (for at least one week, see Figure 3C). On the contrary, treatments that suppress food intake in otherwise normal animals (e.g., such as administering cholecystokinin at the start of every meal) result in the expected reduction of meal size, but with a concomitant increase in meal frequency and little or no change in body weight [32]. A likely explanation for this difference may rely on the fact that intestinal gluconeogenesis, depending on the induction of gluconeogenic enzyme expression, takes place on a lasting basis, decreasing hunger, i.e. through satiety, during the inter-meal period and for the forthcoming meal [7]. On the contrary, cholecystokinin is a satiation hormone, reducing hunger for the associated meal but with no lasting action thereafter. This may explain the compensation of its action by increased meal frequency [32].

To conclude, it should be mentioned here that intestinal gluconeogenesis and its portal-brain sensing might also be causal in the improvement in insulin sensitivity after feeding on protein-enriched diet in rats and after gastric bypass surgery in mice $[23,27]$. This is in line with the improved glucose control previously reported in obese diabetic patients fed on a protein-enriched diet [33], or undergoing gastric bypass surgery [22, 34]. Moreover, it has been suggested, from studies on mice [35] and one GSD1 patient [36], that intestinal G6Pase may be implicated in the absorption of glucose from the intestinal lumen, which may provide an alternative route to the direct transport pathway mediated by glucose transporters 
only. Thus, I-G6pc-/- mice will certainly be very useful in the near future to gain better understanding of the role of intestinal gluconeogenesis in the central control of insulin sensitivity and of intestinal G6Pase in the assimilation of glucose from food.

\section{Acknowledgments}

We would like to thank Dr. Sylvie Robine (Paris, France) for generously providing B6.vill ${ }^{\text {CreERT2 }}$ transgenic mice, the Mouse Clinical Institute (Strasbourg, France) for invaluable help in generating the B6.g6pc ${ }^{\text {lox }}$ mice, Angèle Chamousset and Jean-Michel Vicat for animal care (ALECS, Faculty of Medecine Laennec, Lyon, France) and the members of the CECIL Platform (Faculty of Medecine Laennec, IFR62 Lyon-Est, Lyon, France). This work was funded by research grants from the "Agence nationale de la recherche" (ANR-07MRAR-011-01) and the "Association francophone des glycogénoses". 


\section{References}

[1]Rolls BJ, Hetherington M, Burley VJ. The specificity of satiety: The influence of foods of different macronutrient content on the development of satiety. Physiol Behav 1988;43:145-53.

[2]Barkeling B, Rossner S, Bjorvell H. Effects of a high-protein meal (meat) and a highcarbohydrate meal (vegetarian) on satiety measured by automated computerized monitoring of subsequent food intake, motivation to eat and food preferences. Int $\mathrm{J}$ Obesity 1990;14:743-51.

[3]Booth DA, Chase A, Campbell AT. Relative effectiveness of protein in the late stages of appetite suppression in man. Physiol Behav 1970;5:1299-302.

[4]Leidy HJ, Tang M, Armstrong CLH, Martin CB, Campbell WW. The Effects of Consuming Frequent, Higher Protein Meals on Appetite and Satiety During Weight Loss in Overweight/Obese Men. Obesity (in press) doi:10.1038/oby.2010.203

[5]Veldhorst M, Smeets A, Soenen S, Hochstenbach-Waelen A, Hursel R, Diepvens K, et al. Protein-induced satiety: Effects and mechanisms of different proteins. Physiol Behav 2008;94:300-7.

[6]Westerterp-Plantenga MS. The significance of protein in food intake and body weight regulation. Curr Opin Clin Nutr Metab Care 2003;6:635-8.

[7]Mithieux G, Misery P, Magnan C, Pillot B, Gautier-Stein A, Bernard C, et al. Portal sensing of intestinal gluconeogenesis is a mechanistic link in the diminution of food intake induced by diet protein. Cell Metab 2005;2:321-9.

[8]Croset M, Rajas F, Zitoun C, Hurot JM, Montano S, Mithieux G. Rat small intestine is an insulin-sensitive gluconeogenic organ. Diabetes 2001;50:740-6.

[9]Mithieux G. New data and concepts on glutamine and glucose metabolism in the gut. Curr Opin Clin Nutr Metab Care 2001;4:267-71.

[10]Rajas F, Bruni N, Montano S, Zitoun C, Mithieux G. The glucose-6 phosphatase gene is expressed in human and rat small intestine: regulation of expression in fasted and diabetic rats. Gastroenterology 1999;117:132-9.

[11]Battezzati A, Caumo A, Martino F, Sereni LP, Coppa J, Romito R, et al. Nonhepatic glucose production in humans. Am J Physiol- Endoc M. 2004;286:E129-35.

[12]Yanez AJ, Nualart F, Droppelmann C, Bertinat R, Brito M, Concha, II, et al. Broad expression of fructose-1,6-bisphosphatase and phosphoenolpyruvate carboxykinase provide evidence for gluconeogenesis in human tissues other than liver and kidney. $\mathrm{J}$ Cell Physiol 2003;197:189-97.

[13]Kirchner S, Seixas P, Kaushik S, Panserat S. Effects of low protein intake on extrahepatic gluconeogenic enzyme expression and peripheral glucose phosphorylation in rainbow trout (Oncorhynchus mykiss). Comp Biochem Phys B 2005;140:333-40.

[14]Langhans W, Grossmann F, Geary N. Intrameal hepatic-portal infusion of glucose reduces spontaneous meal size in rats. Physiol Behav 2001;73:499-507.

[15]Tordoff MG, Friedman MI. Hepatic portal glucose infusions decrease food intake and increase food preference. Am J Physiol 1986;251:R192-6.

[16]Tordoff MG, Tluczek JP, Friedman MI. Effect of hepatic portal glucose concentration on food intake and metabolism. Am J Physiol 1989;257:R1474-80.

[17]Adachi A, Shimizu N, Oomura Y, Kobashi M. Convergence of hepatoportal glucosesensitive afferent signals to glucose-sensitive units within the nucleus of the solitary tract. Neurosci Lett 1984;46:215-8

[18]Schmitt M. Influences of hepatic portal receptors on hypothalamic feeding and satiety centers. Am J Physiol 1973;225:1089-95. 
[19]Shimizu N, Oomura Y, Novin D, Grijalva CV, Cooper PH. Functional correlations between lateral hypothalamic glucose-sensitive afferent signals to glucose-sensitive units within the nucleus of the solitary tract. Neurosci Lett 1983;46:215-8.

[20]Mithieux M. A novel function of intestinal gluconeogenesis: Central signaling in glucose and energy homeostasis. Nutrition 2009;25:881-4.

[21]Delaere F, Magnan C, Mithieux G. Hypothalamic integration of portal glucose signals and control of food intake and insulin sensitivity. Diabetes Metab 2010;36:257-62.

[22]Perez-Tilve D, D'Alessio DA, Tschop MH. A sweet spot for the bariatric surgeon. Cell Metab 2008;8:177-9.

[23]Troy S, Soty M, Ribeiro L, Laval L, Migrenne S, Fioramonti X, et al. Intestinal gluconeogenesis is a key factor for early metabolic changes after gastric bypass but not after gastric lap-band in mice. Cell Metab 2008;8:201-11.

[24]Mithieux G, Andreelli F, Magnan C. Intestinal gluconeogenesis: key signal of central control of energy and glucose homeostasis. Curr Opin Clin Nutr Metab Care 2009;12:419-23.

[25]Mutel E, Abdul-Wahed A, Ramamonjisoa N, Stefanutti A, Houberdon I, Cavassila S, et al. Targeted deletion of liver glucose- 6 phosphatase mimics glycogen storage disease type 1a including development of multiple adenomas. J Hepatol 2011;54:529-37.

[26]El Marjou F, Janssen KP, Chang BH, Li M, Hindie V, Chan L, et al. Tissue-specific and inducible Cre-mediated recombination in the gut epithelium. Genesis 2004;39:186-93.

[27]Pillot B, Soty M, Gautier-Stein A, Zitoun C, Mithieux G. Protein feeding promotes redistribution of endogenous glucose production to the kidney and potentiates its suppression by insulin. Endocrinology 2009;150:616-24.

[28]Mithieux G, Vidal H, Zitoun C, Bruni N, Daniele N, Minassian C. Glucose-6-phosphatase mRNA and activity are increased to the same extent in kidney and liver of diabetic rats. Diabetes 1996; 45:891-6.

[29]Mithieux G, Rajas F, Gautier-Stein A. A novel role for glucose- 6 phosphatase in the small intestine in the control of glucose homeostasis. J Biol Chem 2004;279:44231-4.

[30]Chou JY, Jun HS, Mansfield BC. Glycogen storage disease type I and G6Pase $\beta$ deficiency: etiology and therapy. Nat Rev Endocrinol 2010;6:676-88.

[31]Lei KJ, Chen H, Pan CJ, Ward JM, Mosinger B, Jr., Lee EJ, et al. Glucose-6-phosphatase dependent substrate transport in the glycogen storage disease type-1a mouse. Nat Genet 1996;13:203-9.

[32]West DB, Fey D, Woods SC. Cholecystokinin persistently suppresses meal size but not food intake in free-feeding rats. Am J Physiol 1984;246:R776-87.

[33]Gannon MC, Nuttall FQ. Effect of a high-protein, low-carbohydrate diet on blood glucose control in people with type 2 diabetes. Diabetes 2004;53:2375-82.

[34]Thaler JP, Cummings DE. Minireview: Hormonal and metabolic mechanisms of diabetes remission after gastrointestinal surgery. Endocrinology 2009;150:2518-25.

[35]Stümpel F, Burcelin R, Jungermann J, Thorens B. Normal kinetics of intestinal glucose absorption in the absence of Glut2: Evidence for a transport pathway requiring glucose phosphorylation and transfer into the endoplasmic reticulum. Proc Natl Acad Sci USA 2001;98:11330-5.

[36]Santer R, Hillebrand G, Steinmann B, Schaub J. Intestinal Glucose Transport: Evidence for a Membrane Traffic-Based Pathway in Humans. Gastroenterology 2003;124:34-9. 


\section{Figure Captions}

Figure 1. PCR genotype analysis and intestine-specific excision of G6pc exon 3.

(A) Diagram of the floxed $G 6 p c$ allele $\left(G 6 p c^{\text {lox }}\right)$ and the exon 3 deleted $G 6 p c$ allele $\left(G 6 p c^{\text {del }}\right)$. Black rectangles represent exons and the 5'and 3' untranslated sequences are indicated by white rectangles. Lox $\mathrm{P}$ sequences are represented as triangles while flags indicate frt sequences. Exon 3 of $G 6 p c$ was specifically excised by CRE recombinase ( $\left.G 6 p c^{\mathrm{del}}\right)$.

(B) Genomic DNA, extracted from tail of ten day-old mice, was amplified using specific LoxG6pc primers (p2 sense: 5'-GCTCATTCTCACACCTACAGTTGG-3' and p3 antisense: 5'TGTTCCTAACTACTGAGCCATTGCTCC-3'), which yielded products of 486 and 385 bp for the floxed G6pc $\left(G 6 p c^{\text {lox }}\right)$ and the WT $\left(G 6 p c^{\mathrm{w}}\right)$ alleles, respectively. Specific Villin-Cre primers (Sense: 5'-CAAGCCTGGCTCGACGGCC-3' and antisense: 5'CGCGAACATCTTCAGGTTCT-3') were used to amplify a 300 bp Cre fragment. The expected sizes are shown on the left of the panel.

(C) Genomic DNA extracted from intestine, liver and kidney of I-G6pc $c^{-/-}(-)$and WT C57Bl/6J (+/+) mice was amplified using specific G6pc primers (p1 sense: 5'AGGGAGtTGACCAGAGGAACTTTGG-3' and p3 antisense). Fragments of 1189, 1029 and 595 bp correspond to the $G 6 p c^{\text {lox }}, G 6 p c^{\mathrm{w}}$ and $G 6 p c^{\text {del }}$ alleles, respectively. The expected sizes are shown on the left of the panel.

Figure 2. Analysis of G6Pase gene expression in the intestine.

Levels of G6pc (A), G6pt (Slc37a4) (C) and G6pc3 (D) mRNA were measured by RT-qPCR in the intestine of I-G6pc $c^{-/}$(black bars) and wild-type (open bars) mice. The results are expressed as a ratio relative to Rpl19 expression. Data were obtained fourteen weeks after tamoxifen injections from mice fasting for 6 hours and are expressed as means \pm SEM ( $n=8$ 
mice per group). *Values significantly different from WT $(\mathrm{P}<0.01)$. G6Pase activity $(\mathrm{B})$ was assayed in the proximal jejunum of I-G6pc $c^{-/-}(-/-)$and WT (+/+) mice, fed on SED (filled bars) or fed for 3 days on PED (hatched bars). Data were obtained two weeks after tamoxifen injections from mice fasting for 6 hours and are expressed as means \pm SEM ( $n=5$ mice per group). *Values significantly different $(\mathrm{P}<0.01)$.

Figure 3. Evolution of food intake and body weight of I-G6pc $c^{-/-}$mice fed on PED versus SED. Daily food intake expressed in $\%$ of the mean food intake calculated from the consumption of I-G6pc $c^{-/-}$mice over the three preceding days (A), accumulated food intake expressed in kcal (B) and body weight expressed in g (C) of I-G6pc ${ }^{-/-}$(filled squares) and WT (open squares) mice. Mice were fed on SED during the first five days and then on PED for one more week. Data were obtained one week after gene deletion and are expressed as means \pm SEM $(n=9$ mice per group). Values significantly different from WT $\left(\mathrm{P}<0.05^{*}\right)$ are indicated.

Table 1

Oligodeoxyribonucleotide primer sequences for $\mathrm{qPCR}(\mathrm{S}=$ sense and $\mathrm{AS}=$ antisense).

\begin{tabular}{|c|c|}
\hline Name & Sequence \\
\hline $\begin{array}{l}\text { Exon1 } \\
\text { G6pc S }\end{array}$ & 5'-TTACCAAGACTCCCAGGACTG-3' \\
\hline $\begin{array}{l}\text { Exon2 } \\
\text { G6pc AS }\end{array}$ & 5'-GAGCTGTTGCTGTAGTAGTCG-3' \\
\hline G6pt S & 5'-TGGTTGGTCTGGTCAACGTA-3' \\
\hline G6pt AS & 5'-TGCCAAGATAGGTCCCAAAC-3' \\
\hline G6pc3 S & 5'-GCACATTTCCCTCACCAAGT-3' \\
\hline G6pc3 AS & 5'-GGTTGATGGACCAGGAAAGA-3' \\
\hline Rpl 19 S & 5'-AGAAGATTGACCGCCATAT-3' \\
\hline Rpl 19 AS & 5'-TTCGTGCTTCCTTGGTCTTAGA-3' \\
\hline
\end{tabular}


Figure 1

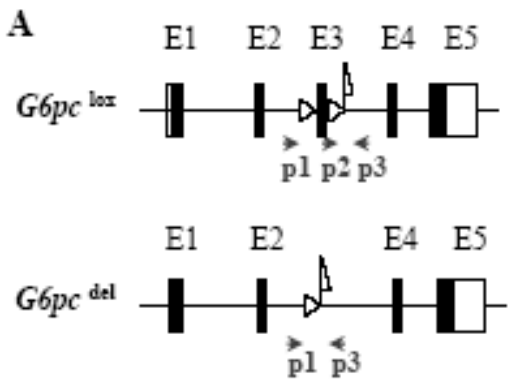

B

$\begin{aligned} & 486 \mathrm{bp} \\ & 385 \mathrm{bp}\end{aligned}-\square-\mid= \pm-G 6 \mathrm{pc}$

$300 \mathrm{bp}-$\begin{tabular}{|l|l|l|}
\hline $\mathbf{D}$ & $\mathbf{D}$ \\
\hline
\end{tabular}

क⿺辶大

C

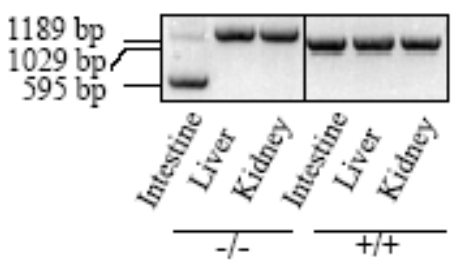


Figure 2

A

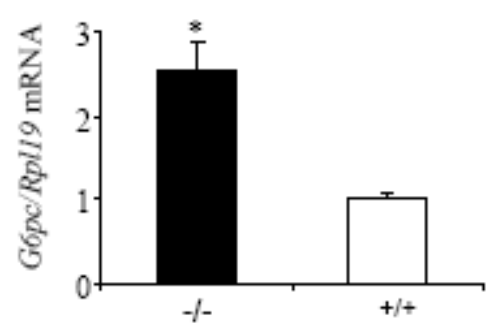

B

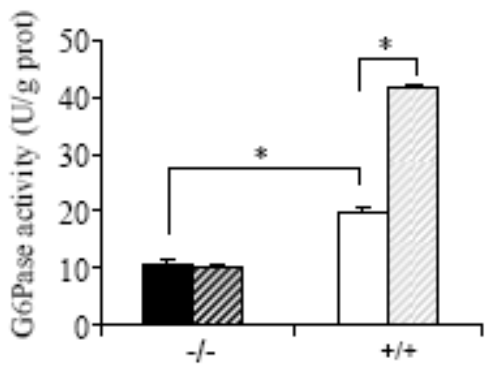

C

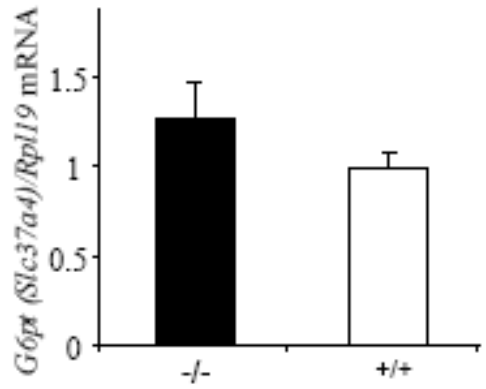

D

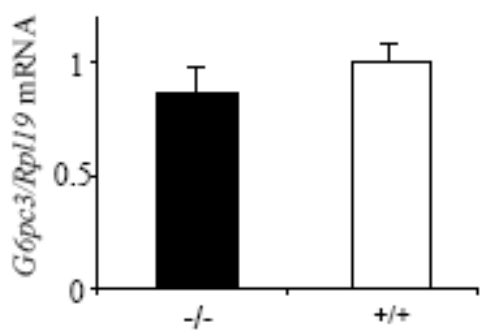


Figure 3

A

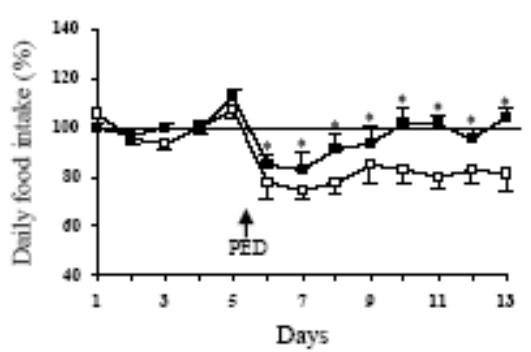

B

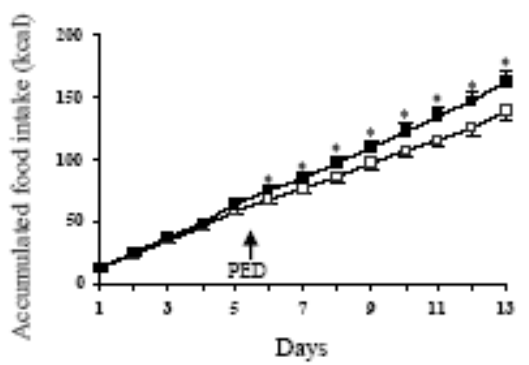

C

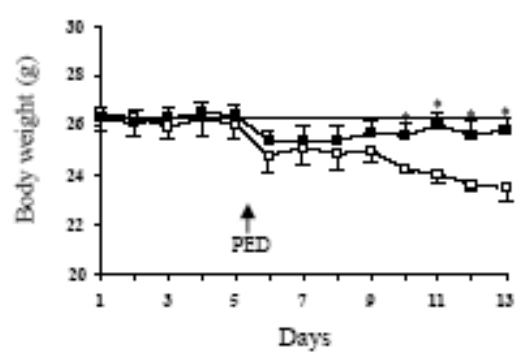

